\title{
https://doi.org/10.30853/manuscript.2018-5.9
}

\section{Пу Цзян}

ПОМОЩЬ СССР КИТАЮ В ОБЛАСТИ ПРОМЫШЛЕННОСТИ В 1950-Е ГГ.

В статье характеризуется помощь СССР в экономическом становлении и развитии Китая в 1950-е гг. Отмечены первоначальная хаотичность и последующая системность оказываемой поддержки, ее многоаспектность и поэтапность. Анализируются материалы о содействии Северо-Востоку Китая Советским Союзом до 1949 г. как первом шаге советско-китайского сотрудничества в последующее великое десятилетие. Приводятся отчеты по выполнению обязательств СССР, раскрывается тема научно-технического взаимодействия между странами, отмечается роль советских специалистов в экономическом восстановлении Китая в исследуемый период.

Адрес статьи: www.gramota.net/materials/9/2018/5/9.html

\section{Источник}

\section{Манускрипт}

Тамбов: Грамота, 2018. № 5(91) C. 45-49. ISSN 2618-9690.

Адрес журнала: www.gramota.net/editions/9.html

Содержание данного номера журнала: www.gramota.net/materials/9/2018/5/

\section{() Издательство "Грамота"}

Информация о возможности публикации статей в журнале размещена на Интернет сайте издательства: www.gramota.net Вопросы, связанные с публикациями научных материалов, редакция просит направлять на адрес: hist@gramota.net 
УДК 94(510)

https://doi.org/10.30853/manuscript.2018-5.9

Дата поступления рукописи: 07.04.2018

В статье характеризуется помощь СССР в экономическом становлении и развитии Китая в 1950-е г2. Отмечены первоначальная хаотичность и последующая системность оказываемой поддержки, ее многоаспектность и поэтапность. Анализируются материаль о содействии Северо-Востоку Китая Советским Союзом до 1949 г. как первом шаге советско-китайского сотрудничества в последуюшее великое десятилетие. Приводятся отчеты по выполнению обязательств СССР, раскрывается тема научно-технического взаимодействия между странами, отмечается роль советских специалистов в экономическом восстановлении Китая в исследуемьй период.

Ключевые слова и фразы: СССР; КНР; тяжелая промышленность; развитие экономики Китая; 1950-е гг.; научно-техническая помощь.

\section{Пу Цзян}

Институт истории Санкт-Петербургского государственного университета pujiang2012@yandex.ru

\section{ПОМОЩЬ СССР КИТАЮ В ОБЛАСТИ ПРОМЫШЛЕННОСТИ В 1950-Е ГГ.}

Промышленная система КНР, построенная за первую и вторую пятилетки, повысила технологический уровень индустриального развития Китая. В отличие от последующих этапов заимствования иностранных технологий, при которых ввод в эксплуатацию оборудования затормаживался неподготовленностью технической базы Китая, промышленное оборудование, приходящее из СССР, снабжалось инструкциями и технической документацией, а также сопровождалось инженерами-техниками, обученными в Советском Союзе или в КНР с помощью советских специалистов. Все это позволило обеспечить эффективный ввод в работу и ремонт предприятий, а также возможность самостоятельно производить аналогичное оборудование для других китайских предприятий в последующие годы. Уровень передаваемых в тот период научно-технических материалов из СССР не на много отставал от передовых мировых достижений (примерно на 3-5 лет) [5, с. 114].

Надо заметить, что с помощью СССР в основном развивался Северо-Восток Китая, и эта выборочность обусловлена несколькими причинами. Во-первых, оборудование из СССР в Китай доставлялось по железной дороге и по магистралям, ранее проложенным по Манчжурии; во-вторых, на Северо-Востоке Китая уже имелась основательная промышленная база, оставленная японцами, а потому Центральный Комитет Коммунистической партии Китая (ЦК КПК) планировал поднимать промышленность, опираясь именно на эту базу. В этой связи стоит заметить, что промышленное развитие Северо-Востока Китая действительно связано с огромным вкладом Японии в этот регион [2], но ни преувеличивать, ни преуменьшать роль Японии не стоит. Во-первых, нельзя забывать о причинах строительства японцами тяжелой промышленности на территории Китая, а во-вторых, в процессе войны и последующего поражения Квантунской армии многие предприятия были разрушены, а оборудование с них было вывезено в СССР как трофейное [8, д. 45, л. 166-168].

Безусловно, благодаря капиталовложениям Японии Китай получил одну из самых развитых в азиатском регионе баз тяжелой промышленности, которая была крупнейшей еще в период Второй мировой войны и оставалась таковой вплоть до конца 1970-х гг., т.е. до начала экономических реформ Дэн Сяопина.

Однако в промышленном восстановлении и развитии северо-востока Китая огромная роль принадлежит и СССР. Стоит заметить, что помощь Советского Союза в этом регионе оказывалась еще до образования КНР - с 1946 г. - с момента разгрома Квантунской армии [Там же д. 38, л. 158-165]. Советские специалисты совместно с советскими же рабочими восстанавливали КВЖД, кораблестроительный завод в Даляне и т.д. Налаживалось пассажирское и грузовое сообщение. Для ускорения процессов восстановления промышленности и для подготовки китайских специалистов, которых очень сильно не хватало, были организованы смешанные советско-китайские общества: «Совкитсудострой» на базе судостроительного и судоремонтного завода г. Дальнего; «Электроэнергетическая советско-китайская компания», занимающаяся восстановлением и эксплуатацией электростанций и электрозаводов; компания «Квантунрыба», занимавшаяся рыбным промыслом, а также соледобычей, эксплуатацией содовых, химических, стекольных и др. заводов. Восстанавливать предприятия на Ляодунском полуострове, торговлю и транспорт народно-демократическим организациям помогала советская военная администрация [6, с. 86].

Разобщенность районов Китая во второй половине 1940-х гг. на те, где помощь СССР уже оказывалась, и те, где экономическое положение оставалось тяжелым, усугублялась положением и в финансовом секторе экономики. На территории Ляодунского полуострова был успешно скорректирован когда-то высокий уровень инфляции, который все еще сохранялся во всем остальном Китае. Бюджет Квантунского областного управления благодаря советским и советско-китайским промышленным предприятиям сводился с превышением доходов над расходами, а потому денежное обращение было упорядочено, и цены на товары снижены [7, д. 1240, л. 68]. В Маньчжурии же в целом, несмотря на успехи в восстановлении промышленности и КВЖД, в связи с военными действиями, привести в порядок денежное обращение не получалось. Именно поэтому в начале 1949 г. ввести единую валюту даже на территории подконтрольной КПК не представлялось 
возможным [Там же, л. 69]. Однако центральное народное правительство все же планировало в течение ближайших 2-3 лет восстановить промышленность до ее прежнего высшего уровня и построить заводы общего и сельскохозяйственного машиностроения и частично достигло поставленной цели [8, д. 77, л. 198].

Первое масштабное обсуждение помощи СССР Китаю до образования КНР проходило в январе-феврале 1949 г. в Сибайпо во время тайного визита А. И. Микояна в ставку КПК. Кроме политических тем, в беседах с Мао Цзэдуном, Чжоу Эньлаем, Чжу Дэ, Жэнь Биши и др., поднимались вопросы содействия в развитии промышленности Китая: в частности, о строительстве заводов по производству вооружений. Большую роль в советско-китайском сотрудничестве КПК отводила Маньчжурии. «Жэнь Биши подчеркнул, что в своих народнохозяйственных планах они большое место уделяют Маньчжурии с целью превратить ее в кузницу обороноспособности страны. Она должна производить автомашины, самолеты, танки и др. виды вооружения. Так же он сказал, что в промышленном освоении Маньчжурии они надеются на помощь со стороны Сов. Союза» [4, с. 72]. Основными формами советского участия в восстановлении и развитии китайской тяжелой промышленности были: создание совместных экономических предприятий, выдача кредитов, передача опыта промышленного строительства, снабжение соответствующими методическими и методологическими материалами, командирование специалистов по различным отраслям хозяйства.

Китаю требовалась помощь и в эксплуатации месторождений редких видов металла (уран, магний, молибден, алюминий), не разрабатывавшихся на его территории до этого времени. Была большая потребность в высококвалифицированных специалистах (например, на Аньшаньском металлургическом комбинате были вынуждены все еще пользоваться услугами японских специалистов).

Следующим этапом помощи в восстановлении экономики Китая был визит делегации КПК под руководством Лю Шаоци в Москву в июне-августе 1949 г. В протокольной записи приема этой делегации И. В. Сталиным обсуждался вопрос о кредите в размере 300 млн долларов, который давался под 1\% годовых. Интересно, что соглашение о предоставлении кредита подписывалось между ЦК ВКП(б) и ЦК КПК. Обсуждался также вопрос о специалистах, которые должны были отправиться в Китай вместе с возвращающейся туда делегацией ЦК КПК. Сталин также подчеркивал, что Китаю необходимо создать флот и пообещал помочь в этом вопросе [Там же, с. 85-86].

Делегацией КПК во главе с Лю Шаоци был подготовлен доклад (от 4 июля 1949 г.) об основных проблемах внутренней и внешней политики КПК, который был представлен лично Сталину. В нем раскрывалось экономическое положение Китая, которое нельзя было назвать удовлетворительным (слабый уровень развития коммуникаций, наличие сфер влияния империалистов, феодальная раздробленность в стране), вследствие чего не удавалось образовать единую систему экономики, а потому местным правительствам были предоставлены широкие права самоуправления [11, с. 151-162]. Кроме того, у КПК на тот момент были большие сложности с формированием государственного аппарата, что не позволяло подойти к восстановлению экономики системно. Так, до образования КНР, со стороны КПК просьбы о помощи чаще всего направлялись напрямую Сталину и имели не системный, а ситуативный характер. Например, в телеграмме от 16 мая 1949 г. Гао Ган просит срочно предоставить 385 т дымогарных труб, от которых зависит производство паровозов, а значит и план восстановления Северо-Востока Китая [7, д. 1240, л. 72].

14 февраля 1950 г. были подписаны Договор о дружбе, союзе и взаимной помощи, соглашение о Китайской Чанчуньской железной дороге, Порт-Артуре и Дальнем, соглашение о предоставлении Советским Союзом Китайской Народной Республике долгосрочного экономического кредита и др. Договор предусматривал всемерное развитие и укрепление экономических и культурных связей двух стран в соответствии с принципами равноправия, взаимных интересов, а также уважения государственного суверенитета и территориальной целостности, равно как и невмешательства в дела другой стороны [11, с. 274-280].

В записке П. Кумыкина о ходе выполнения соглашений, подписанных 14 февраля 1950 г. с приложением справок по торгово-экономическим вопросам советско-китайских отношений от 11 августа 1952 г., мы находим данные о выполнении обязательств по поставкам оборудования комплектных предприятий в 1952 г. в КНР по сведениям на 1 августа 1952 г.

В этих документах говорится, что оборудование уже поставлено на 21 объект: и это 54\% от общего плана, намеченного соглашением. В справке о выполнении проектных работ и об оборудовании, направленном в КНР для всех комплектных предприятий, по состоянию на 1 августа 1952 г. имеется следующая информация: «Общий объем поставок оборудования и оказания технической помощи по обязательствам оценивается в сумме 1.430 млн. руб., включая принятые 2 августа сего года на Комиссии по внешней торговле 24 объекта на сумму 314 млн. руб., из них расчетам по кредиту 622 млн. руб.

На 1 августа 1952 года выполнено на сумму 238,6 млн. руб., в том числе с расчетом по кредиту на 169,5 млн. руб.

Всего имеется обязательств по поставке оборудования и оказанию технической помощи Китаю по 105 предприятиям, в том числе 87 предприятий с поставкой оборудования. Принято к поставке 11 августа с.г. еще 24 объектов» [8, д. 50, л. 1-47].

Также приведена справка о советских специалистах, направленных в КНР для оказания технической помощи. «Командировано в 1950-1952 гг. всего 639 чел., и в их числе 143 только в 1952 г. Закончили работу и возвратились в СССР 292 чел. Продолжают работать в Китае 347 чел. Дополнительно ожидается командирования в 1952 году 56 чел.» [Там же, л. 45]. 
К записке П. Кумыкина прикладывалась также справка о количестве китайских граждан, командированных в СССР для прохождения производственно-технического обучения. «Количество китайских граждан подлежащих обучению по подписанным соглашениям или контрактам всего 169 чел., прибывших в СССР для обучения в 1951 году 91 чел., ожидаемых к прибытию в СССР для обучения в 1952 г. - 78 чел. (Согласно Постановлению Совета Министров СССР от 6.9.1951 г. №3313-1569 - 3 чел. Согласно Постановлению Совета Министров СССР от 6.11.1951 г. №4394-1973 - 89 чел. Согласно Постановлению Совета Министров СССР от 7.6.1952 г. №2621-997 - 77 чел.)» [Там же, л. 46].

В еще одной справке предоставлялись сведения о передаче технической документации КНР по данным на 9 августа 1952 г. Из них следует, что планировалось передать: всего - 427 единиц документов, уже передано - 390, ожидает исполнения - 37 единиц. Также приводятся сведения об имеющихся дополнительных просьбах Китайской стороны, а именно: о новых поставках оборудования, об оказании технической помощи в строительстве новых комплектных предприятий, о технической помощи без поставок оборудования и т.д.

В первые годы после образования КНР (1949-1953 гг.) научно-технические связи между СССР и Китаем носили фрагментарный характер и были односторонними, т.е. Советский Союз оказывал помощь, откликаясь на отдельные просьбы КНР. До 1953 г. между двумя странами не было подписано какого-либо специального многолетнего соглашения по оказанию научно-технической помощи, но, несмотря на это, уже с 1950 г. по 1953 г. - на основании решения Дальневосточной комиссии - советская сторона направила 599 комплектов научно-технической документации в Китай, из них в 1950 г. - 30 комплектов, в 1951 г. - 308, 1952 г. - 169, 1953 г. - 92 комплекта [13, с. 13]. В составе переданных документов были комплексные проекты по капитальному строительству, чертежи на оборудование и машины, разработки и описания технологических процессов, ведомственная техническая документация.

Научно-техническое сотрудничество в качестве отдельного положения упоминается в соглашении «Об оказании помощи Китаю в строительстве промышленных предприятий, намечаемых пятилетним планом КНР» от 15 мая 1953 года [9, д. 995, л. 26-32]. К видам технической помощи отнесено выполнение проектных работ, научно-техническое сопровождение строительства и реконструкции предприятий черной и цветной металлургии, угольной, нефтяной, химической промышленности, электростанций, предприятий машиностроения, легкой, военной и других отраслей экономики Китая.

Первое же межправительственное соглашение о научно-техническом сотрудничестве СССР и КНР было подписано 12 октября 1954 г. [12, с. 304]. В документе говорится об обмене опытом во всех отраслях народного хозяйства, в которых имеются актуальные разработки в научно-технической сфере. Обе стороны договорились передавать друг другу техническую документацию, обмениваться соответствующей информацией, а также командировать специалистов для оказания технической помощи и ознакомления с достижениями обеих стран в научно-технической области. В документе также оговаривается, что передача документации будет производиться сторонами безвозмездно с оплатой лишь фактических расходов, связанных с изготовлением копий документов. Для разработки мероприятий по осуществлению сотрудничества образована советско-китайская комиссия.

Первая сессия советско-китайской комиссии по научно-техническому сотрудничеству между СССР и КНР состоялась 28 декабря 1954 г. [10, д. 910, л. 1-6]. Было условлено проводить ее заседания два раза в год и обмениваться информацией об использовании странами производственного опыта и технической документации один раз в год. За период с 1954 г. по 1966 г. состоялось 15 сессий, по результатам которых было подписано 15 протоколов. Как видно из тем, обсуждаемых на сессиях, помощь СССР Китаю оказывалась по узловым проблемам, и с каждым годом количество этих тем (с последующей передачей комплектов документации) только росло.

Управление по делам научно-технического сотрудничества (УНТС) решало такие вопросы, как общее руководство и координация научно-технических связей, разработка мероприятий, подготовка протоколов комиссии, обмен документацией, командирование советских специалистов и ученых, прием иностранных специалистов, введение расчетов с зарубежными странами и т.д. [13, с. 16].

Надо заметить, что содействие в строительстве предприятий, инженерных сооружений и других промышленных объектов, которое осуществлялось СССР, являлось частью научно-технического сотрудничества, т.е. наряду с поставками оборудования предоставлялась и техническая документация по ним, а также командировались специалисты, которые помогали освоить полученную технику и разобраться с сопутствующими документами. Передавался технологический и производственный опыт.

Более того, в ходе строительства промышленных объектов Советским Союзом, Китаю безвозмездно передавались лицензии на производство машин, оборудования и различных видов изделий, проекты по капитальному строительству, чертежи поставленного из СССР оборудования и машин, а также описания технологических процессов. По общим подсчетам за первую пятилетку было отправлено в Китай полной технической документации на 156 крупных предприятий, которые строились в этот период с помощью СССР [Там же, с. 27].

18 января 1958 г. было подписано еще одно соглашение об оказании Советским Союзом помощи Китаю по решению 122 проблем в научно-технической области по 16-ти направлениям, среди которых есть такие как: жаропрочные сплавы, редкие металлы и комплексное использование железорудных ископаемых (7 проблем); комплексное использование угля, газа, нефти (3 проблемы); проектирование крупногабаритных и точных машин, приборов и исследование технологических процессов (8 проблем); новая техника в химической промышленности (21 проблема) [12, с. 390]. Это соглашение по сравнению с предыдущим (от 12 октября 1954 г.) 
было более масштабным. Кроме того, к концу 1950-х гг. количество проблем, по которым оказывалась помощь, возросло со 122 до 163 тем.

На фоне начавшегося периода «большого скачка» стали расширяться и сферы научно-технического сотрудничества между СССР и КНР. Так, обмен опытом в отраслях тяжелой промышленности между двумя странами в это время достиг наибольшего масштаба. Более того, по рекомендации IV-VII сессий Советскокитайской комиссии (1956-1958 гг.) и по соглашению от 18 января 1958 г. начали устанавливаться прямые контакты между конкретными советскими и китайскими министерствами и ведомствами [Там же, с. 391 ].

В этот период также меняется и характер запросов на научно-техническую документацию и специалистов из СССР. Изначально заявки китайской стороны преимущественно касались документов на технологические процессы в машиностроительной продукции (станки, электромоторы, прессы, насосы, инструменты) и документов на технологические процессы по некоторым видам продукции в других областях промышленности. В ходе же осуществляемого СССР строительства новых и реконструкции старых предприятий Китай стал направлять заявки на: типовую проектную документацию по строительству металлургических предприятий; на научно-техническую документацию по производству крупного металлургического оборудования; на технологическую документацию в области машиностроения и других областей народного хозяйства, обеспечивающих тяжелую промышленность сырьем и оборудованием; на рабочие чертежи для изготовления машин и оборудования [13, с. 31-32].

Руководствуясь политикой «большого скачка», Китай требовал значительного увеличения советских обязательств по межправительственным соглашениям, которые в соответствии с решением VII сессии Советско-китайской комиссии (1958 г.) увеличились вдвое по сравнению с предыдущим годом. Так, уже к середине 1959 г. обязательства СССР по ведущим отраслям народного хозяйства КНР составляли свыше 6 тыс. тем, что было равно объему обязательств за пять предыдущих лет вместе взятых [Там же, с. 32].

За 1958-1960 гг. СССР передал КНР 7307 комплектов проектной и технической документации, и все это в основном для отраслей тяжелой промышленности, в том числе по соглашению от 12 октября 1954 г. - 3096 комплектов, а по соглашению 18 января 1958 г. - 4211 комплектов [Там же, с. 33].

Можно говорить о том, что по советско-китайским соглашениям о техническом содействии в Китае было построено свыше 300 крупных гражданских и военных объектов, полностью укомплектованных. По советским проектам на капитальное строительство за 1950-е гг. Китаем было спроектировано свыше 400 промышленных предприятий, всего же Китай получил за годы сотрудничества свыше 1400 таких проектов.

За 1950-е гг. СССР предоставил Китаю 11 долгосрочных кредитов на общую сумму, составляющую примерно 2 млрд инвалютных рублей. На эти деньги в основном поставлялось различное оборудование, оказывалась помощь в запуске большого количества крупных предприятий, проводились проектные и разведывательные работы. Помимо предоставленных финансовых средств, СССР всесторонне содействовал строительству еще 211 крупных предприятий более чем на 11 млрд юаней, и чуть позже, в конце 1950-х гг., СССР взял на себя строительство 125 крупных предприятий стоимостью 5 млрд рублей [6, с. 103].

До сих пор существует расхождение в подсчетах количества промышленных предприятий, построенных с помощью СССР. Так, китайский историк Пэн Мин в своей работе, изданной 1989 г., насчитал 304 предприятия [Цит. по: 1, с. 334], а в монографии О. Б. Борисова и Б. Г. Колоскова указано 400 полномасштабных предприятий и отдельных цехов [3, с. 174]. По подсчетам М. В. Александровой таких предприятий можно насчитать 537 единиц [Там же, с. 330].

Подводя некоторые итоги, можно говорить о том, что помощь СССР Китаю имела на первых этапах точечный и хаотичный характер, постепенно приобретая планомерность и системность. Оказанное содействие было многосторонним, т.е. охватывало все аспекты экономического восстановления молодого государства, что и позволило заложить прочный фундамент дальнейшего становления КНР. Безусловно, СССР преследовал свои цели, но главная из них - экономически сильный Китай и партнерские, равноправные отношения с ним.

\section{Список источников}

1. Александрова М. В. Экономика Северо-Восточного Китая и советская помощь КНР в 50-х годах XX века // Китай в мировой и региональной политике. История и современность: ежегодное издание / отв. ред.-сост. Е. И. Сафронова. М.: ИДВ РАН, 2013. Вып. ХVIII. С. 326-348.

2. Александрова М. В. Японский капитал и его значение в развитии промышленности Северо-Восточного Китая (конец XIX в. - 1945 г.) // Китай в мировой и региональной политике. История и современность: ежегодное издание / отв. ред.-сост. Е. И. Сафронова. М.: ИДВ РАН, 2014. Вып. ХІХ. С. 336-358.

3. Борисов О. Б., Колосков Б. Г. Советско-китайские отношения. 1945-1980. Изд-е 3-е, доп. М.: Мысль, 1980.638 с.

4. Ледовский А. М. СССР и Сталин в судьбах Китая. Документы и свидетельства участника событий: 1937-1952. М.: Памятники исторической мысли, 1999. 344 с.

5. Муромцева 3. А. Путь и проблемы промышленного возвышения КНР (1949-2011 гг.) // Вековой путь Китая к прогрессу и модернизации: к 100-летию Синхайской революции: доклады XIX международной научной конференции «Китай, китайская цивилизация и мир. История, современность, перспективы» (г. Москва, 19-21 октября 2011 г.). М.: ИДВ РАН, 2012. С. 112-119.

6. Проблемы и противоречия индустриального развития КНР / под ред. М. И. Сладковского. М.: Мысль, 1974.240 с.

7. Российский государственный архив социально-политической истории (РГАСПИ). Ф. 82. Оп. 2.

8. РГАСПИ. Ф. 84. ОП. 1.

9. Российский государственный архив экономики (РГАЭ). Ф. 4372. Оп. 11. 
10. РГАЭ. Ф. 9493. Оп. 1.

11. Русско-китайские отношения в XX веке: документы и материалы: в 5-ти т.: в 2-х кн. М.: Памятники исторической мысли, 2005. Т. 5. Советско-китайские отношения. Кн. 2. 1949 - февраль 1950 г. / отв. ред. С. Л. Тихвинский. 608 с.

12. Советско-китайские отношения: 1917-1957: сборник документов / отв. ред. И. Ф. Курдюков, В. Н. Никифоров, А. С. Перевертайло. М.: Издательство восточной литературы, 1959. 469 с.

13. Филатов Л. В. Экономическая оценка научно-технической помощи Советского Союза Китаю (1949-1966). М.: Наука; Главная редакция восточной литературы, 1980. 167 с.

\title{
SOVIET ASSISTANCE TO CHINESE INDUSTRY IN THE 1950S
}

\author{
Pu Jiang \\ Saint Petersburg University \\ pujiang2012@yandex.ru
}

\begin{abstract}
The article describes Soviet assistance in the economic formation and development of China in the 1950s. The initial chaos and subsequent systemic nature of the support provided, its multidimensionality and stage-by-stage character are noted. The materials on the promotion of Northeast China by the Soviet Union prior to 1949 as the first step of Soviet-Chinese cooperation in the subsequent great decade are analyzed. The author presents reports on the fulfillment of the obligations of the USSR. The theme of scientific and technical cooperation between the countries is revealed, and the role of Soviet specialists in China's economic recovery during the period under study is observed.
\end{abstract}

Key words and phrases: The USSR; The PRC; heavy industry; development of China's economy; the 1950s; scientific and technical assistance.

УДК 93

Дата поступления рукописи: 24.04.2018

https://doi.org/10.30853/manuscript.2018-5.10

В статье рассматриваются организация и состав чиновников Коломенского уездного казначейства во второй половине XIX - начале XX в. На основе анализа законодательства Российской империи и архивньх документов Центрального государственного архива г. Москвы, в частности штатных формуляров, прослежень изменения структуры и функций уездных казначейств в целом, выявлены состав и статус служащих Коломенского уездного казначейства, изучень и обобщены сведения об их образовании, ротации, материальном положении, а также системе поощрений.

Ключевые слова и фразы: Московская губерния; Коломенское уездное казначейство; нормативно-правовая база; формулярные списки; служебный состав.

Соза Лилия Нисоновна, к.и.н., доцент

Государственный соииально-гуманитарный университет, г. Коломна

livaso@list.ru

\section{ОРГАНИЗАЦИЯ И СЛУЖЕБНЫЙ СОСТАВ КОЛОМЕНСКОГО УЕЗДНОГО КАЗНАЧЕЙСТВА ВТОРОЙ ПОЛОВИНЫ ХІХ - НАЧАЛА ХХ В.}

В изучении истории города как территориально-административной единицы одним из важнейших сюжетов является деятельность финансовых учреждений и, в частности, губернского и уездного казначейств. Уездные казначейства, взаимодействовавшие со второй половины XIX века с городскими думами, земскими учреждениями, Государственным и общественными банками, оказывали значительное влияние на экономическую жизнь городского поселения.

Укажем, что в современной исторической науке вопросам деятельности губернских и уездных казначейств уделено недостаточно внимания. Обследование фондов региональных архивов позволило историкам обратиться к деятельности губернских и уездных казначейств на территориях Сибири [8], Камчатки [7], Мордовии [19], Вологодской (Усть-Сысольский уезд) [11], Нижегородской [5; 9], Саратовской [1], Курской [2; 8], Вятской губерний [6; 14] и др. В перечисленных работах уделяется внимание служебному составу, функциям губернских и уездных казначейств, деятельности сберегательных касс при казначействах. Заметим, большинство названных исследований посвящено деятельности казначейств на территории крупных регионов или отдельных губерний. К сожалению, работы о функционировании указанных финансовых органов на территории Московской губернии отсутствуют. Предлагаемая статья ликвидирует указанный пробел применительно к казначейству Коломенского уезда.

При исследовании темы использовался обширный круг источников как опубликованных, так и архивных. К числу опубликованных источников (в зависимости от происхождения и формы отражения исторических реалий) можно отнести: во-первых, законодательные акты второй половины XVIII - конца XIX в., опубликованные в Полном собрании законов Российской империи; во-вторых, справочно-статистические 